\title{
The effects of nanosilver on egg quality traits in laying Japanese quail
}

\author{
Amjad Farzinpour • Naser Karashi
}

Received: 31 October 2011/Accepted: 20 March 2012/Published online: 1 April 2012

(c) The Author(s) 2012. This article is published with open access at Springerlink.com

\begin{abstract}
Silver nanoparticles could prove to be a valuable alternative raw material for antibiotics and disinfectants as it is relatively free of adverse effects. Nanosilver is now been put to practical use in commonly used items, such as, clothes, electric home appliances, and electronic industry, but has not been widely applied in the medical or pharmacological fields. This study was designed to investigate the effects of nanosilver on egg quality traits in laying Japanese quail in completely randomized design with four treatments and six repetitions at $0,4,8$ and 12 ppm of silver nanoparticle levels. Eggs collected daily and egg parameters, including egg weight, length, width; yolk weight and eggshell thickness were examined. The effect of the different silver nanoparticle levels was determined using the General Linear Model of SAS procedure, whilst differences between the groups were determined using least significant difference test. Results indicated that silver nanoparticles at all levels caused significantly reduce of yolk weight and hen-day egg production for each week than the control treatment $(P<0.05)$, whilst silver nanoparticle had no significant effect on egg weight, egg length and width and eggshell thickness.
\end{abstract}

Keywords Nanosilver - Quail · Egg quality ·

Hen-day egg production

\section{Introduction}

Silver nanoparticles could prove to be a valuable alternative raw material for antibiotics and disinfectants.

\footnotetext{
A. Farzinpour $(\varangle) \cdot$ N. Karashi

Department of Animal Science, Faculty of Agriculture,

University of Kurdistan, Sanandaj, Iran

e-mail: amjadfarzinpour@gmail.com
}

Nanosilver is now been put to practical use in commonly used items, such as, clothes, electric home appliances, and electronic industry, but has not been widely applied in the medical or pharmacological fields (Shin et al. 2007). Silver nanoparticles show a broad band of antimicrobial effectiveness. The Pars Nano Nasb Company in Iran has been developing the technology of applying silver nanoparticles to impose the efficiency of reducing bacterial contamination in the production of chicken and other animals. Therefore, the nanosilver is used today more as a high disinfectant in poultry production farms in Iran (Shahbazzadeh et al. 2009). Although many studies have been done to evaluate the impact of nanosilver in birds, the effects exerted by silver nanoparticles administration on the overall reproductive performances of avian species have not been fully studied, especially when the egg and meat of birds are the main protein sources for human. The present study investigated the effects of nanosilver on body weight (BW), egg production, egg quality parameters and mortality using a laboratory animal model, the Japanese quail.

\section{Materials and methods}

Seventy-two Japanese quail layers $(n=72)$ were used in the present study and divided into 4 groups or treatments at 8 weeks of age. Data were mean of six replicate groups of three female Japanese quail each. Three female quails were assigned to each of 24 cages and were housed in a $45 \times 16 \times 15-\mathrm{cm}$ battery cage pen. To minimize the effects of body weight and physiological status in the egg laying cycle, only females from the same hatch, of similar body weights (between 130 and $135 \mathrm{~g}$ ) were used. The birds were reared in a light-proof environmentally controlled house at $25^{\circ} \mathrm{C}$ with a photoperiod of 14L:10D. The 
birds were supplied with commercial laying quail diets and tap drinking water ad libitum. Silver nanoparticles (Nanocid L2000, Colloidal Liquid, No. 357) were purchased from Nano Nasb Pars Company (Tehran, Iran). Physicochemical properties of the silver nanoparticles included formula: $\mathrm{TiO}_{2}-\mathrm{Nano} \mathrm{Ag}$, concentration, $\mathrm{TiO}_{2} \sim 99 \% \mathrm{WT}$; Nano Ag $\sim 1 \% \mathrm{WT}$, nano Ag particles size distribution, $50 \mathrm{~nm}$ max; physical state, solid-powder; appearance, white-cream; particle diameter, $0.2 \mu \mathrm{m}$; specific area, $10.42 \mathrm{~m}^{2} / \mathrm{g}$; temperature endurance, up to $2,000{ }^{\circ} \mathrm{C}$. Four levels: $0,4,8$ and $12 \mathrm{ppm}$ of nanosilver were used in the drinking water during the experimental period. We determined the $0,4,8$ and $12 \mathrm{ppm}$ just by simple dilution from Nanocid. Every week the body weight (BW) of each bird was measured individually. The number of eggs produced and dead birds (if any) under each group were recorded every morning for 5 weeks. The collected eggs and the yolk weight were weighed. The hen-day egg production was recorded every week. The hen-day egg production were then recorded daily at the same time and calculated as follows: total number of eggs collected divided by total number of live hens per day in each group. Egg shell quality was measured as deformation (abnormal eggs), shell weight, shell membrane weight, shell thickness and egg shape index. The yolks were carefully separated from the egg whites with forceps and blotting papers, and weighed. The shell membranes were completely removed from the egg shell using forceps after 30-min soaking in tap water. The membrane weight was taken after air drying in room temperature when the samples attained nearly constant weight. Eggshell thickness was measured with a digital micrometer (Mitutoyo, Japan). Length and breadth were measured using a vernier caliper and values were used to calculate the shape index (breadth $\times 100 /$ length). The effect of the different silver nanoparticle levels data were evaluated using a $6 \times 4 \times 3$ (replicate $\times$ treatment $\times$ samples) factorial design. Data were subjected to the General Linear Models (GLM) procedures of SAS (SAS Institute, 1990). Means were separated using the least significant difference test. Significance was assumed at $P<0.05$.

\section{Results}

The percentage of hen-day egg production in each week of the birds that received 4, 8 and $12 \mathrm{ppm}$ of nanosilver were significantly $(P<0.05)$ lower than that of the control during 10-12 weeks (Fig. 1). Although neither the egg weight (Table 1) and eggshell thickness (Table 3), nor egg shape index (Table 4) was found to be markedly affected by nanosilver administration up to the end of the experimental period. In birds that received $12 \mathrm{ppm}$ of nanosilver there was a significant decrease $(P<0.05)$ in yolk weight

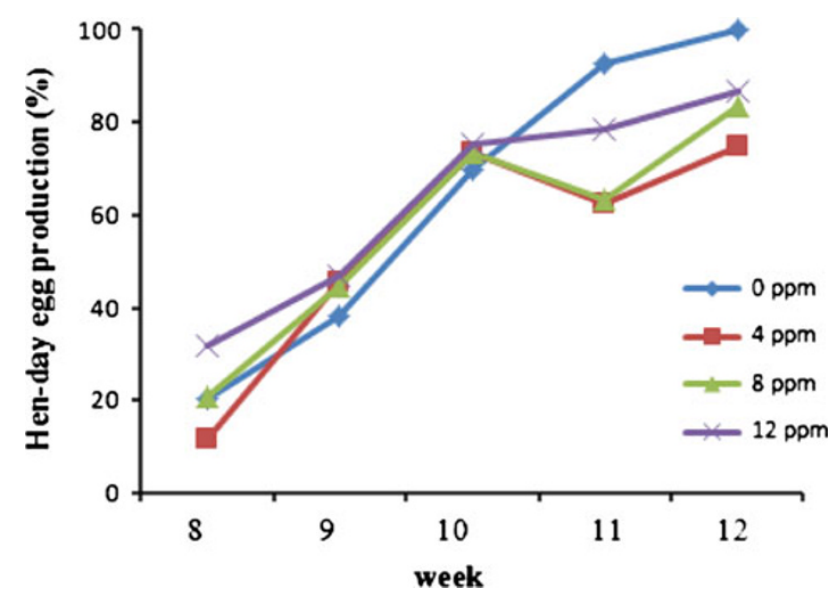

Fig. 1 Effect of nanosilver on hen-day egg production for each week in laying Japanese. The data of 10-12 weeks of the control are significantly different from those of the corresponding weeks of 4,8 and $12 \mathrm{ppm}$ of nanosilver $(P<0.05)$

throughout the 12 weeks (Table 2) compared to the control group and birds that received 4 and 8 ppm of nanosilver and other weeks. The shell membrane weight was not affected in the treatment groups when were compared with the control group. There was no significant main effect of treatment groups on mortality (Table 5). The body weight was similar and there were no differences between all groups during experimental period.

\section{Discussion}

The use of antibiotics in animal production has caused the development of antibiotic-resistant pathogen microorganisms. Recently, in many countries and especially in Iran, antibiotic-based growth promoters have been prohibited. Nevertheless, intensification of animal production and reduced immunity of highly productive animals require a search for new growth-promoting alternatives to antibiotics. Poultry species of very intensive growth kept in highly industrialized production systems are vulnerable to microbial infections affecting health and performance of animals. Numerous investigations have been carried out to develop feed additives (e.g., probiotics, herbs, preservatives), which would guarantee the profitability of poultry production and which are not dangerous to human health as in the case of growth promoters with antibiotic properties. Nanotechnological methods allow the production of nanoparticles of noble metals, which may exhibit unique biological properties. Noble metals such as silver and its ions have long been known to have unique anti-bacterial properties, but even small doses of ionic silver may be toxic, limiting the use of silver as an anti-bacterial agent in animal production (Sawosz et al. 2007; Grodzik and 
Table 1 Effects of nanosilver on egg weight in laying Japanese quail

\begin{tabular}{llllll}
\hline Level $(\mathrm{ppm})$ & \multicolumn{1}{l}{ Weeks } & 10 & & \\
\cline { 2 - 6 } & 8 & 9 & $11.6 \pm 0.10(26)$ & $11.7 \pm 0.24(26)$ & $11.4 \pm 0.39(42)$ \\
\hline 0 & $9.3 \pm 0.12(14)$ & $10.1 \pm 0.78(24)$ & $11.2 \pm 0.59(30)$ & $11.1 \pm 0.63(22)$ & $10.9 \pm 0.53(30)$ \\
4 & $9.1 \pm 0.25(8)$ & $10.0 \pm 0.79(30)$ & $11.4 \pm 0.31(26)$ & $11.3 \pm 0.44(22)$ & $11.1 \pm 0.32(41)$ \\
8 & $9.5 \pm 0.11(14)$ & $10.2 \pm 0.61(24)$ & $11.2 \pm 0.41(28)$ & $11.2 \pm 0.52(26)$ & $11.4 \pm 0.23(42)$ \\
\hline 2 & $9.7 \pm 0.20(20)$ & $10.2 \pm 0.54(24)$ & & &
\end{tabular}

Values $(\mathrm{g})$ are mean $\pm \mathrm{SD}$ of egg weight in parentheses

Table 2 Effects of nanosilver on egg yolk weight in laying Japanese quail

\begin{tabular}{llllll}
\hline Level $(\mathrm{ppm})$ & \multicolumn{1}{l}{ Weeks } & & & \\
\cline { 2 - 6 } & 8 & 9 & 10 & 11 & 12 \\
\hline 0 & $32.1 \pm 1.20(14)$ & $29.4 \pm 1.10(12)$ & $27.6 \pm 2.32(13)$ & $29.9 \pm 1.22(13)$ & $34.9 \pm 2.23(15)$ \\
4 & $33.0 \pm 1.02(8)$ & $28.0 \pm 1.52(15)$ & $29.6 \pm 1.02(15)$ & $30.5 \pm 1.17(10)$ & $34.0 \pm 2.14(15)$ \\
8 & $32.6 \pm 0.12(14)$ & $27.6 \pm 1.12(12)$ & $28.1 \pm 1.14(13)$ & $31.0 \pm 1.03(10)$ & $30.0 \pm 2.51(15)$ \\
12 & $29.5 \pm 1.52(10)$ & $27.5 \pm 1.62(12)$ & $30.6 \pm 1.00(14)$ & $29.4 \pm 1.33(13)$ & $27.0 \pm 2.12 *(15)$
\end{tabular}

Values (\% to egg weight) are mean \pm SD of the number of eggs in parentheses

$* P<0.05$, when compared with the control in the same column

Table 3 Effects of nanosilver on eggshell thickness in laying Japanese quail

\begin{tabular}{|c|c|c|c|c|c|}
\hline \multirow[t]{2}{*}{ Level (ppm) } & \multicolumn{5}{|l|}{ Weeks } \\
\hline & 8 & 9 & 10 & 11 & 12 \\
\hline 0 & $0.198 \pm 0.03$ & $0.196 \pm 0.06(6)$ & $0.197 \pm 0.05(6)$ & $0.206 \pm 0.08$ & $0.215 \pm 0.01(7)$ \\
\hline 4 & $0.193 \pm 0.07(6)$ & $0.199 \pm 0.03(7)$ & $0.202 \pm 0.01(7)$ & $0.211 \pm 0.03(5)$ & $0.213 \pm 0.03(7)$ \\
\hline 8 & $0.200 \pm 0.01(7)$ & $0.201 \pm 0.01$ & $0.201 \pm 0.01(6)$ & $0.207 \pm 0.06(5)$ & $0.211 \pm 0.05$ (7) \\
\hline 12 & $0.195 \pm 0.11$ & $0.197 \pm 0.03(7)$ & $0.196 \pm 0.08$ & $0.209 \pm 0.05(7)$ & $0.217 \pm 0.01$ \\
\hline
\end{tabular}

Values $(\mathrm{mm})$ are mean \pm SD of the number of eggs in parentheses

Table 4 Effects of nanosilver on egg shape index in laying Japanese quail

\begin{tabular}{llllll}
\hline Level $(\mathrm{ppm})$ & \multicolumn{1}{l}{ Weeks } & & & \\
\cline { 2 - 6 } & 8 & 9 & 10 & 11 & 12 \\
\hline 0 & $80.7 \pm 0.31(11)$ & $80.9 \pm 0.70(34)$ & $80.1 \pm 0.04(34)$ & $79.5 \pm 0.83(28)$ & $79.5 \pm 0.41(73)$ \\
4 & $77.6 \pm 0.37(7)$ & $80.6 \pm 0.37(23)$ & $79.6 \pm 0.41(46)$ & $78.1 \pm 0.03(14)$ & $77.4 \pm 0.98(53)$ \\
8 & $82.8 \pm 0.84(15)$ & $79.2 \pm 0.32(32)$ & $78.2 \pm 0.42(41)$ & $79.2 \pm 0.96(17)$ & $79.1 \pm 0.84(62)$ \\
12 & $80.1 \pm 0.34(28)$ & $80.6 \pm 0.83(42)$ & $79.2 \pm 0.81(44)$ & $78.9 \pm 0.02(23)$ & $79.2 \pm 0.04(63)$ \\
\hline
\end{tabular}

Values (\%) are mean \pm SD of the number of eggs in parentheses

Sawosz 2006). However, the toxicity of Ag can be eliminated, when used in nanoparticle form (Grodzik and Sawosz 2006). Nanoparticles are structures from 1 to $100 \mathrm{~nm}$. Due to their small size, the total surface area of the particles exposed in solution is maximized, resulting in the highest activity per unit of weight. Increased exposure to nanoparticles being produced in large-scale industry facilities elicits concerns for the toxicity of certain classes of nanoparticles. In particular, the oral toxicity of silver nanoparticles is of particular concern to ensure public and consumer health. Due to the intensive commercial application of silver nanoparticles, health risk assessment of this nanoparticle is of great importance. New investigations demonstrated Ag-NPs caused toxicity in various cell-lines. Silver caused lethal damage to hepatocytes in rats and finally leading to cell death (Baldi et al. 1988). Abnormal elevation of blood silver levels, Argyria-like symptoms and hepatotoxicity following the use of nanosilver-coated 
Table 5 Effects of nanosilver on mortality in laying Japanese quail

\begin{tabular}{lllllll}
\hline $\begin{array}{l}\text { Level } \\
(\mathrm{ppm})\end{array}$ & \multicolumn{2}{l}{ Weeks } & & & $\begin{array}{c}\text { Total } \\
8-12\end{array}$ \\
\cline { 2 - 6 } & 8 & 9 & 10 & 11 & 12 & $8-12$ \\
\hline 0 & 1 & 1 & 0 & 4 & 0 & 6 \\
4 & 1 & 1 & 2 & 1 & 0 & 5 \\
8 & 1 & 1 & 3 & 1 & 0 & 6 \\
12 & 1 & 1 & 2 & 1 & 0 & 5 \\
\hline
\end{tabular}

Values (numbers) are the number of dead birds

dressings for burns in clinical application have been reported (Trop et al. 2006). Silver not only causes dermal and cosmetic toxic effects, but also causes death in animals (Panyala et al. 2008). Soto et al. (2005) have recently shown that silver nanoparticles can be nearly $50 \%$ more toxic than chrysolite asbestos. Nanoparticles, such as silver nanoparticles, are showing severe toxic effects on the male reproductive system. The identified research suggests that nanoparticles cross the blood-testes barrier and are deposited in the testes (McAuliffe and Perry 2007). A prolonged exposure to silver has shown toxic effects on CNS such as cerebral ataxia (Panyala et al. 2008). The available experimental animal studies have shown that silver is absorbed in and metabolized in soft tissues (Panyala et al. 2008). According to Cheng et al. (2004), Zhang and Sun (2007), silver ions can also enter into the human body through the female genital tract. Silver nanoparticles have been shown to damage brain cells (Hussain et al. 2006); liver cells (Hussain et al. 2005). Silver and silver salts are distributed around the body and they accumulated and show some toxic effects in organs and tissues (Panyala et al. 2008). Silver ions show a high affinity for thiol in the liver (Drake and Hazelwood 2005). Today silver nanoparticles can be applied to animal feeding as feed additive (Fondevila et al. 2009). In an experiment with broiler chicks, dosage of metallic silver nanoparticles for 5 weeks was continued by 7 days of non-supplemented period. Silver retention was $0.035,0.031$ and $0.045 \mu \mathrm{g} / \mathrm{g}$ in muscular tissue and 0.113 , 0.086 and $0.185 \mu \mathrm{g} / \mathrm{g}$ for the same treatments in liver tissue for 20, 30 and 40 silver ppm in diet, respectively (Fondevila et al. 2009). Only 5 out of 10 animals given 20 and $30 \mathrm{ppm}$ silver showed detectable concentration in muscles, while 6 and 7 out of 10 animals with the same treatments showed silver concentration in the liver (Fondevila et al. 2009). We could consider the liver to be an integral part of that system because that is where the egg yolk lipid is formed. Laying birds require a normal liver to sustain maximum egg production over time. There are many factors that can adversely affect egg production. Egg production can be affected by such factors as feed consumption (quality and quantity), water intake, intensity and duration of light received, parasite infestation, disease, toxins and numerous management and environmental factors. Although the silver as an antibiotic requirement of birds is relatively low, adequate levels are essential; and excessive amounts are toxic. The decreased hen-day egg production and yolk weight found in quails that received $12 \mathrm{ppm}$ nanocide might be the result of hepatotoxic effects of silver. This idea coincided with the reports of some researchers who found silver nanoparticles to be restrictedly caused lethal damage to hepatocytes (Baldi et al. 1988; Hussain et al. 2005). As a matter of fact, nanomaterials are widely used in many fields such as the chemical industry, biomedicine and poultry industry as a disinfectant and use of silver nanoparticles for a long time in layer or broiler breeder farms may have side effects on female birds and their reproductive performances. Therefore, we hypothesized that nanosilver may affect the egg production in laying quail as a laboratory animal model. Our findings showed that administration of $12 \mathrm{ppm}$ of nanosilver caused a significant decrease in yolk weight. The percentage of hen-day egg production for each week of the birds that received 4, 8 and 12 ppm of nanosilver was significantly lower than the control during 10-12 weeks. Our results indicate the importance of the length of silver nanoparticles exposure on egg production and yolk weight in laying quails during a long period of exposure to drinking water containing nanoparticles. The decreasing yolk weight and egg production within the late week after nanocide administration indicated silver toxicity was a chronic effect. It seems that colloidal nanosilver has an effect on the egg production of the quail.

\section{Conclusion}

In conclusion, this investigation demonstrated for the first time that colloidal silver nanoparticles influenced egg production of quails; however, water containing $12 \mathrm{ppm}$ silver nanoparticles significantly decreased the yolk weight. Furthermore, 4, 8 and $12 \mathrm{ppm}$ nanocide decreased egg production. Finally, further research is required to elucidate the underlying mechanisms of silver nanoparticles on egg production, liver and reproductive performances. Determination of silver nanoparticle residues in meat and egg are also suggested in future studies.

Open Access This article is distributed under the terms of the Creative Commons Attribution License which permits any use, distribution and reproduction in any medium, provided the original author(s) and source are credited.

\section{References}

Baldi C, Minoia C, Di Nuici A, Capodaglio E, Manzo L (1988) Effects of silver in isolated rat hepatocytes. Toxicol Lett 41:261-268 
Cheng D, Yang J, Zhao Y (2004) Antibacterial materials of silver nanoparticles application in medical appliances and appliances for daily use. Chin Med Equip J 4:26-32

Drake PL, Hazelwood KJ (2005) Exposure-related health effects of silver and silver compounds: a review. Ann Occup Hyg 49:575-585

Fondevila M, Herrer R, Casallas MC, Abecia L, Ducha JJ (2009) Silver nanoparticles as a potential antimicrobial additive for weaned pigs. Animal Feed Sci Technol 150:259-269

Grodzik M, Sawosz E (2006) The influence of silver nanoparticles on chicken embryo development and bursa of fabricius morphology. J Animal Feed Sci 15:111-114

Hussain SM, Hess KL, Gearhart JM, Geiss KT, Schlager JJ (2005) In vitro toxicity of nanoparticles in BRL 3A rat liver cells. Toxicol In Vitro 19:975-983

Hussain SM, Javorina MK, Schrand AM, Duhart HM, Ali SF, Schlager JJ (2006) The interaction of manganese nanoparticles with PC-12 cells induces dopamine depletion. Toxicol Sci 92:456-463

McAuliffe ME, Perry MJ (2007) Are nanoparticles potential male reproductive toxicants? A literature review. Nanotoxicology 1:204-210

Panyala NR, Peña-méndez EM, Havel J (2008) Silver or silver nanoparticles: a hazardous threat to the environment and human health? J Appl Biomed 6:117-129
Sawosz E, Grodzik M, Grodzik M, Zielińska M, Sysa P, Szmidt M, Niemiec T, Chwalibog A (2007) Influence of hydrocolloidal silver nanoparticles on gastrointestinal microflora and morphology of enterocytes of quails. Arch Animal Nutr 61:444-451

Shahbazzadeh D, Ahari H, Mohammad Rahimi N, Dastmalchi F, Soltani M, Fotovat M, Rahmannya J, Khorasani N (2009) The effects of nanosilver (nanocid) on survival percentage of rainbow trout (Oncorhynchus mykiss). Pak J Nutr 8:1178-1179

Shin SH, Ye MK, Kim HS, Kang HS (2007) The effects of nanosilver on the proliferation and cytokine expression by peripheral blood mononuclear cells. Int Immunopharmacol 7:1813-1818

Soto Kf, Carrasco A, Powell TG, Garza KM, Murr LE (2005) Comparative in vitro cytotoxicity assessment of some manufactured nanoparticulate materials characterized by transmission electron microscopy. J Nanoparticle Res 7:145-169

Trop M, Novak M, Rodl S, Hellbom B, Kroell W, Goessler W (2006) Silver-coated dressing acticoat caused raised liver enzymes and argyria-like symptoms in burn patient. J Trauma 60:648-652

Zhang Y, Sun J (2007) A Study on the bio-safety for nano-silver as anti-bacterial materials. Chin J Med Instrum 31:35-38 